RNA/DNA co-analysis from human menstrual blood and vaginal secretion stains Results of a fourth and fifth collaborative EDNAP exercise

Haas, Claus; Hanson, E; Anjos, M J; Ballantyne, K N; Banemann, R; Bhoelai, B; Borges, E; Carvalho, M; Courts, C; De Cock, G; Drobnic, K; Dötsch, M; Fleming, R; Franchi, C; Gomes, I; Hadzic, G; Harbison, S A; Harteveld, J; Hjort, Benjamin Benn; Hollard, C; Hoff-Olsen, P; Hüls, C; Keyser, C; Maroñas, O; McCallum, N; Moore, D; Morling, Niels; Niederstätter, H; Noël, F; Parson, W; Phillips, C; Popielarz, C; Roeder, A D; Salvaderi, L; Sauer, E; Schneider, Peter M.; Shanthan, G; Court, D Syndercombe; Turanská, M; van Oorschot, R A H; Vennemann, M; Vidaki, A; Zatkalíková, L; Ballantyne, J

Published in:

Forensic science international. Genetics

DOI:

10.1016/j.fsigen.2013.09.009

Publication date:

2014

Citation for published version (APA):

Haas, C., Hanson, E., Anjos, M. J., Ballantyne, K. N., Banemann, R., Bhoelai, B., Borges, E., Carvalho, M., Courts, C., De Cock, G., Drobnic, K., Dötsch, M., Fleming, R., Franchi, C., Gomes, I., Hadzic, G., Harbison, S. A., Harteveld, J., Hjort, B. B., ... Ballantyne, J. (2014). RNA/DNA co-analysis from human menstrual blood and vaginal secretion stains: Results of a fourth and fifth collaborative EDNAP exercise. Forensic science international. Genetics, 8(1), 203-12. https://doi.org/10.1016/j.fsigen.2013.09.009 


\title{
RNA/DNA co-analysis from human menstrual blood and vaginal secretion stains: Results of a fourth and fifth collaborative EDNAP exercise
}

\author{
C. Haas ${ }^{\mathrm{a}, *}$, E. Hanson ${ }^{\mathrm{b}}$, M.J. Anjos ${ }^{\mathrm{k}}$, K.N. Ballantyne ${ }^{\mathrm{w}}$, R. Banemann ${ }^{\mathrm{r}}$, B. Bhoelai ${ }^{\mathrm{e}}$, \\ E. Borges ${ }^{j}$, M. Carvalho ${ }^{k}$, C. Courts ${ }^{h}$, G. De Cock $^{\mathrm{d}}$, K. Drobnic ${ }^{\mathrm{p}}$, M. Dötsch ${ }^{\mathrm{r}}$, R. Fleming ${ }^{\mathrm{f}}$, \\ C. Franchi ${ }^{\mathrm{x}}$, I. Gomes ${ }^{\mathrm{n}}$, G. Hadzic ${ }^{\mathrm{p}}$, S.A. Harbison ${ }^{\mathrm{f}}$, J. Harteveld ${ }^{\mathrm{e}}$, B. Hjort ${ }^{\mathrm{v}}$, C. Hollard ${ }^{\mathrm{i}}$, \\ P. Hoff-Olsen ${ }^{g}$, C. Hüls ${ }^{1}$, C. Keyser ${ }^{\mathrm{i}}$, O. Maroñas ${ }^{\mathrm{t}}$, N. McCallum ${ }^{\mathrm{m}}$, D. Moore ${ }^{\mathrm{q}}$, N. Morling ${ }^{\mathrm{v}}$, \\ H. Niederstätter ${ }^{o}$, F. Noël ${ }^{\mathrm{d}}$, W. Parson ${ }^{\circ}$, C. Phillips ${ }^{\mathrm{t}}$, C. Popielarz ${ }^{\mathrm{j}}$, A.D. Roeder ${ }^{\mathrm{s}}$, \\ L. Salvaderi ${ }^{y}$, E. Sauer ${ }^{\text {h }}$, P.M. Schneider ${ }^{\mathrm{n}}$, G. Shanthan ${ }^{\mathrm{g}}$, D. Syndercombe Court ${ }^{\mathrm{c}}$, \\ M. Turanská ${ }^{\text {, }}$, R.A.H. van Oorschot ${ }^{\text {w }}$, M. Vennemann ${ }^{1}$, A. Vidaki ${ }^{c}$, L. Zatkalíková ${ }^{u}$,
} J. Ballantyne ${ }^{\mathrm{b}}$

a Institute of Legal Medicine, University of Zurich, Switzerland

${ }^{\mathrm{b}}$ National Center for Forensic Science, University of Central Florida, Orlando, USA

${ }^{\mathrm{c}}$ Department of Forensic and Analytical Science, King's College London, UK

${ }^{\mathrm{d}}$ National Institute for Criminalistics and Criminology, Brussels, Belgium

e Netherlands Forensic Institute, The Hague, The Netherlands

${ }_{\mathrm{f}}^{\mathrm{f}}$ Institute of Environmental Science and Research Ltd., Auckland, New Zealand

${ }^{\mathrm{g}}$ Department of Forensic Genetics, Norwegian Institute of Public Health, Oslo, Norway

${ }^{\mathrm{h}}$ Institute of Legal Medicine, University of Bonn, Germany

institute of Legal Medicine, University of Strasbourg, France

${ }^{\mathrm{j}}$ Institut National de Police Scientifique, Laboratoire de Police Scientifique de Lyon, France

${ }^{\mathrm{k}}$ Forensic Genetic and Biology Service, National Institute of Legal Medicine and Forensic Sciences, Coimbra, Portugal

${ }^{1}$ Institute of Legal Medicine, Medical School Hannover, Germany

${ }^{\mathrm{m}}$ Centre for Forensic Science, Department of Pure and Applied Chemistry, University of Strathclyde, Glasgow, Scotland, UK

${ }^{\mathrm{n}}$ Institute of Legal Medicine, Faculty of Medicine, University of Cologne, Germany

${ }^{\circ}$ Institute of Legal Medicine, Innsbruck Medical University, Austria

${ }^{\mathrm{p}}$ National Forensic Laboratory, Ljubljana, Slovenia

${ }^{\mathrm{q}}$ Innovation and Development Team, LGC Forensics, Teddington, UK

${ }^{\mathrm{r}}$ Bundeskriminalamt, Wiesbaden, Germany

s Orchid Cellmark Ltd., Abingdon, UK

${ }^{\mathrm{t}}$ Forensic Genetics Unit, Institute of Legal Medicine, University of Santiago de Compostela, Spain

${ }^{\mathrm{u}}$ Institute of Forensic Science, Ministry of the Interior, Department of Biology and DNA Analysis, Slovenska Lupca, Slovakia

${ }^{v}$ Section of Forensic Genetics, Department of Forensic Medicine, Faculty of Health and Medical Sciences, University of Copenhagen, Denmark

${ }^{\mathrm{w}}$ Victoria Police Forensic Services Department, Melbourne, Victoria, Australia

${ }^{\mathrm{x}}$ RIS Carabinieri, Sezione di Biologia di Roma, Italy

${ }^{\mathrm{y}}$ NGB Genetics di Bologna, Italy

\section{A R T I C L E I N F O}

\section{Article history:}

Received 2 September 2013

Accepted 28 September 2013

\section{Keywords:}

Forensic science

Body fluid identification

Vaginal secretion

Menstrual blood

\begin{abstract}
A B S T R A C T
The European DNA Profiling Group (EDNAP) organized a fourth and fifth collaborative exercise on RNA/ DNA co-analysis for body fluid identification and STR profiling. The task was to identify dried menstrual blood and vaginal secretion stains using specific RNA biomarkers, and additionally test 3 housekeeping genes for their suitability as reference genes. Six menstrual blood and six vaginal secretion stains, two dilution series (1/4-1/64 pieces of a menstrual blood/vaginal swab) and, optionally, bona fide or mock casework samples of human or non-human origin were analyzed by 24 participating laboratories, using RNA extraction or RNA/DNA co-extraction methods. Two novel menstrual blood mRNA multiplexes were used: MMP triplex (MMP7, MMP10, MMP11) and MB triplex (MSX1, LEFTY2, SFRP4) in conjunction with a housekeeping gene triplex (B2M, UBC, UCE). Two novel mRNA multiplexes and a HBD1 singleplex were
\end{abstract}

\footnotetext{
* Corresponding author at: Institute of Legal Medicine, Forensic Genetics, University of Zürich, Winterthurerstrasse 190,8057 Zürich, Switzerland.

Tel.: +4144635 56 56; fax: +41446356858.

E-mail address: cordula.haas@irm.uzh.ch (C. Haas).
} 
Housekeeping genes mRNA profiling used for the identification of vaginal secretion: Vag triplex (MYOZ1, CYP2B7P1 and MUC4) and a Lactobacillus-specific Lacto triplex (Ljen, Lcris, Lgas). The laboratories used different chemistries and instrumentation and all were able to successfully isolate and detect mRNA in dried stains. The simultaneous extraction of RNA and DNA allowed for positive identification of the tissue/fluid source of origin by mRNA profiling as well as a simultaneous identification of the body fluid donor by STR profiling, also from old and compromised casework samples. The results of this and the previous collaborative RNA exercises support RNA profiling as a reliable body fluid identification method that can easily be combined with current STR typing technology.

(c) 2013 Elsevier Ireland Ltd. All rights reserved.

\section{Introduction}

Conventional tests for the identification of blood, saliva and semen are based on enzymatic and immunological reactions of cell specific enzymes and antigens, but many of these tests lack specificity [1]. Recently two screening tests for the identification of menstrual blood were described, that utilize antibodies for fibrinfibrinogen degradation products (latex agglutination test, D-dimer assay) [2,3]. Neither test has been confirmed and validated for forensic use. Up to now no reliable presumptive test for the identification of vaginal secretion exists [1]. The analysis of cellspecific mRNA expression is a confirmative method for the identification of body fluids [1,4-37]. The suitability of mRNA profiling assays has also been demonstrated for old and environmentally compromised samples $[17,18,35]$. Recently, three collaborative exercises were performed by the European DNA Profiling Group (EDNAP - http://www.isfg.org/EDNAP) in order to evaluate the robustness and reproducibility of mRNA profiling for blood, saliva and semen identification: (1) evaluation of three blood-specific markers (HBB, SPTB and PBGD) using singleplex reactions [38]; (2) evaluation of seven blood-specific markers using two multiplex systems, a 'high sensitivity' duplex (HBB, HBA) and a 'moderate sensitivity' pentaplex (ALAS2, CD3G, ANK1, PBGD and SPTB) [39] and (3) a saliva triplex including the markers HTN3, STATH and MUC7 and a semen pentaplex allowing the detection and differentiation of sperm (PRM1, PRM2) and seminal plasma (PSA, SEMG1 and TGM4), the latter of which is necessary for the identification of semen from azoospermic men [40]. Most laboratories, some of which had no prior experience with RNA, were able to successfully isolate and analyze RNA from the provided samples. While sensitivity varied between laboratories, the method proved to be reproducible and sensitive using different analytical strategies.

A fourth and fifth collaborative exercise was organized by the Institute of Legal Medicine, University of Zürich, Switzerland, on behalf of EDNAP in order to test forensically suitable menstrual blood and vaginal secretion markers, respectively. In addition 3 housekeeping genes were evaluated. In a preliminary study performed by the Florida and Zürich laboratories, various menstrual blood and vaginal secretion mRNA markers described in the literature $[11,19,23,34,36]$ were evaluated in terms of sensitivity, specificity and performance with casework samples. For this study, 7 menstrual blood, 7 vaginal secretion and 3 housekeeping gene markers were tested, 16 of which were deemed most suitable for forensic use (Table 1). Hs202072 was seldom detectable during pretesting and therefore excluded from further analysis. In these exercises, the following multiplexes were developed and provided to the participating laboratories: (1) two menstrual blood multiplexes, MMP triplex (MMP7, MMP10, MMP11) and MB triplex (MSX1, LEFTY2, SFRP4) in conjunction with a housekeeping gene triplex (B2M, UBC, UCE); (2) two vaginal secretion triplexes, including human Vag triplex (MYOZ1, CYP2B7P1 and MUC4) and bacterial Lacto triplex (Ljen, Lcris, Lgas) and a HBD1 singleplex. These multiplexes were developed for ease of use in the exercises and have not been validated for routine use.

The exercises included the analysis of mock casework samples $(2 \times 8)$, dilution series of menstrual blood and vaginal secretions and optional additional bona fide or mock casework samples from the participating laboratories. The housekeeping gene markers were included in order to evaluate their use as positive controls for

Table 1

List of evaluated mRNA markers for the identification of vaginal secretion, menstrual blood and housekeeping genes.

\begin{tabular}{|c|c|c|}
\hline \multicolumn{2}{|l|}{ Gene } & \\
\hline \multicolumn{3}{|c|}{ Menstrual Blood } \\
\hline MMP7 & matrix metalloproteinase 7 & \multirow{3}{*}{ MMP triplex } \\
\hline MMP10 & matrix metalloproteinase 10 & \\
\hline MMP11 & matrix metalloproteinase 11 & \\
\hline MSX1 & msh homeobox 1 & \multirow{3}{*}{ MB triplex } \\
\hline LEFTY2 & left-right determination factor 2 & \\
\hline $\begin{array}{l}\text { SFRP4 } \\
\text { Hs202072* }\end{array}$ & $\begin{array}{l}\text { secreted frizzled-related protein } 4 \\
\text { uncharacterized LOC100505776 }\end{array}$ & \\
\hline \multicolumn{3}{|c|}{ Vaginal secretion } \\
\hline MYOZ1 & myozenin-1 & \multirow{3}{*}{ Vag triplex } \\
\hline CYP2B7P1 & $\begin{array}{l}\text { cytochromeP } 450 \text {, family } 2 \text {, subfamily } \mathrm{B} \text {, } \\
\text { polypeptide } 7 \text { pseudogene } 1\end{array}$ & \\
\hline MUC4 & mucin 4 & \\
\hline HBD1 & human beta-defensin 1 & \multirow[t]{2}{*}{ HBD1 singleplex } \\
\hline Ljen & Ljen [16s ribosomal RNA] & \\
\hline Lcris & Lcris [16S-23S intergenic spacer region] & \multirow[t]{2}{*}{ Lacto triplex } \\
\hline Lgas & Lgas [16S-23S intergenic spacer region] & \\
\hline \multicolumn{2}{|c|}{ Housekeeping genes } & \multirow{4}{*}{ HKG triplex } \\
\hline B2M & Beta-2 microglobulin & \\
\hline UBC & Ubiquitin C & \\
\hline UCE & Ubiquitin conjugating enzyme & \\
\hline
\end{tabular}

*Not sensitive. 
successful RNA extraction/reverse transcription for future work. The expression of these housekeeping genes was additionally tested in blood, saliva and semen dilution series. Several housekeeping gene markers have already been tested on body fluids $[19,24,32,37]$, but up to now, no marker has been described that is universally suitable for all body fluids. Saliva and semen normally show reduced expression of housekeeping genes, probably because spermatozoids contain little cytoplasm and few ribosomes and the desquamated cells of the buccal mucosa have almost no cell metabolism [19].

Here we present data from 20 and 23 laboratories participating in the fourth and fifth collaborative exercise on the identification of menstrual blood and vaginal secretion respectively.

\section{Materials and methods}

\subsection{Samples and materials provided}

The organizing laboratory (Institute of Legal Medicine, University of Zürich, Switzerland) sent one set of samples for each exercise to the participating laboratories.

Exercise 4 included stains 1-8 (menstrual blood, non-menstrual blood, Table 2), a menstrual blood dilution series (1/4-1/64 of a menstrual blood swab) and 3 dilution series of blood, semen and saliva (1-0.001 $\mu \mathrm{l}$ blood, 5-0.04 $\mu \mathrm{l}$ semen, 25-0.2 $\mu \mathrm{l}$ saliva). Menstrual blood from 6 different donors (for 6 stains and 1 dilution series) was collected on swabs or on sanitary towels (4 fresh samples and 3 that had been stored for up to 5 years at room temperature in the dark). Additional fresh samples not containing menstrual blood (blood, saliva, vaginal secretion) were provided by 3 female donors. Semen (stored frozen for 5 years, thawed and placed on swabs) was provided by 1 male donor. For stain 2, a quarter of a swab containing $40 \mu$ l EDTA-blood (corresponds to about $10 \mu \mathrm{l}$ blood per stain) was provided. Stain 5 was a quarter of a vaginal secretion swab. For the blood, semen and saliva dilution series, samples were diluted in $0.9 \% \mathrm{NaCl}$ to a final volume of $5 \mu \mathrm{l}$ per sample and placed on swabs.

Exercise 5 included stains 9-16 (vaginal secretion, non-vaginal secretion, Table 2) and a vaginal secretion dilution series (1/4-1/ 64 of a vaginal secretion swab). Vaginal secretion from 6 different donors (for 6 stains and 1 dilution series) was collected on swabs, on a sanitary towel or in underpants, 5 of them were fresh and 2 had been stored for up to 5 years at room temperature in the dark. Fresh non-vaginal secretion samples (urine, saliva) were provided by 2 female donors. Stain 11 was half of a swab that was immersed into liquid urine and stain 15 was half of a buccal swab.

In both exercises, the laboratories were asked, but not required, to examine additional samples: (1) bona fide or mock casework material that could include human and/or non-human menstrual blood and vaginal secretion stains or (2) other forensically relevant body fluids (e.g. blood, semen, saliva).

HPLC-purified primers were purchased from Microsynth (St. Gallen, Switzerland). The organizing laboratory prepared primer mixes for the multiplexes and aliquots were provided to the participating laboratories for use in amplification reactions (see below). The primers and samples were sent non-refrigerated by Fedex or DHL (exercise 4, arrival within 1-2 days, except 1 parcel that was 20 days in transit; exercise 5 , arrival within 1-3 days, except 2 parcels that were 8 and 10 days in transit).

\subsection{1. $R N A(/ D N A$ co-)extraction and reverse transcription}

The participating laboratories were asked to use the entire swab or stain for extraction (RNA only or RNA/DNA co-extraction). The organizing laboratory provided an example protocol for extraction and reverse transcription. The laboratories could, however, use methods of their own choice. The example protocols were described previously [38,39].

\subsubsection{RNA- and DNA-quantification}

Participating laboratories were asked to quantify RNA using one of the following methods: Quant-iT ${ }^{\mathrm{TM}}$ RiboGreen ${ }^{\circledR}$ RNA Assay kit (Invitrogen) using a fluorescence microplate reader (high and low range protocol option) [11], Quant-iT ${ }^{\mathrm{TM}}$ RNA assay kit (Invitrogen) using the Qubit fluorometer [26] or Bioanalyzer (Agilent) [20]. Laboratories were able to quantify DNA using a quantification system of their own choice.

\subsection{Endpoint $P C R$}

The primer sets and amplicon lengths are shown in Table S1. The forward primers of the menstrual blood and vaginal secretion

Table 2

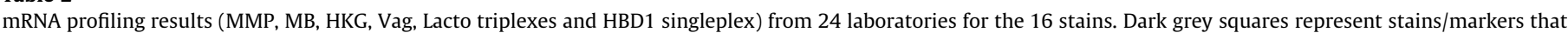

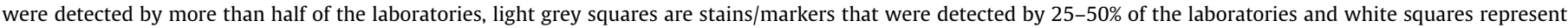
stains/markers that were detected by $<25 \%$ of the laboratories.

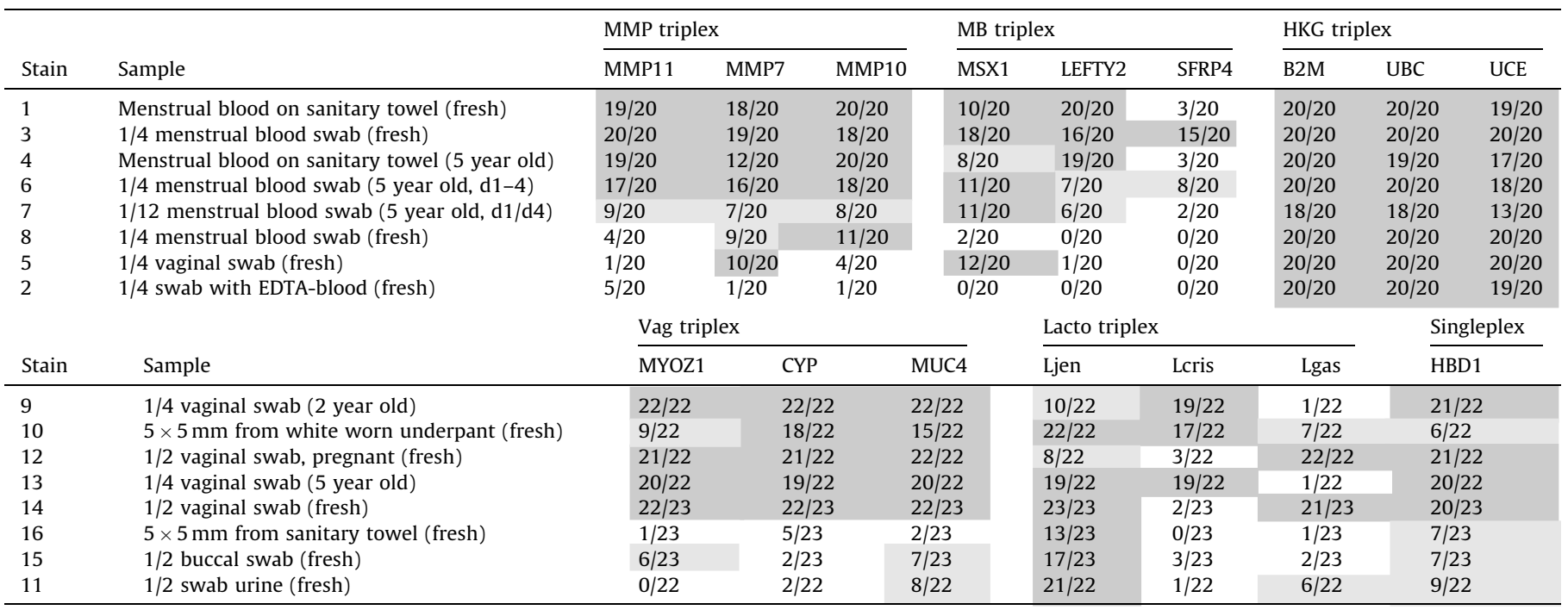


markers were $5^{\prime}$-labeled with FAM. The HKG forward primers were 5'-labeled with the NED-analogue ATTO550.

The following amplification conditions were recommended: MMP, MB, HKG, Vag, Lacto triplexes: The $25 \mu \mathrm{l}$ reaction mix contained $2 \mu \mathrm{l}$ cDNA, $2.5 \mu \mathrm{l} 10 \times$ primer mix (see below), $12.5 \mu \mathrm{l}$ $2 \times$ Multiplex PCR Mastermix (Multiplex PCR kit, QIAGEN), $2.5 \mu \mathrm{l}$ Q-Solution (Multiplex PCR kit; QIAGEN), $5.5 \mu \mathrm{l} \mathrm{H}_{2} \mathrm{O}$. HBD1 singleplex: The $25 \mu \mathrm{l}$ reaction mix contained $5 \mu \mathrm{l}$ cDNA, $2.5 \mu \mathrm{l}$ $10 \times$ PCR Buffer II, $2.5 \mu \mathrm{l}$ dNTPs $\left(2.5 \mathrm{mM}\right.$ each), $3 \mu \mathrm{l} \mathrm{MgCl}_{2}$ (25 mM), $2 \mu \mathrm{l} 12.5 \times$ primer mix, $0.4 \mu \mathrm{l}$ AmpliTaq Gold ${ }^{\circledR}(5 \mathrm{U} /$ $\mu \mathrm{l}$ ) and $9.6 \mu \mathrm{H}_{2} \mathrm{O}$ (all singleplex reagents from Life Technologies). Sterile water was used in place of cDNA for no-template controls.

The $10 \times$ primer mixes were prepared using the following concentrations: MMP triplex: $2 \mu \mathrm{M}$ each; MB triplex: MSX1 $5 \mu \mathrm{M}$, SFRP4 $5 \mu \mathrm{M}$, LEFTY2 $2 \mu \mathrm{M}$; Vag triplex: $2 \mu \mathrm{M}$ each; Lacto triplex: $2 \mu \mathrm{M}$ each; HKG triplex: B2M $2 \mu \mathrm{M}$, UBC $2 \mu \mathrm{M}$, UCE $5 \mu \mathrm{M}$. The $12.5 \times$ primer mix for the HBD1 singleplex was $20 \mu \mathrm{M}$.

The cycling conditions were as follows: $M M P, M B, H K G, \mathrm{Vag}$, Lacto triplexes: the initial denaturation was at $95^{\circ} \mathrm{C}$ for $15 \mathrm{~min}$, followed by 35 cycles of $94{ }^{\circ} \mathrm{C} 30 \mathrm{~s}, 55^{\circ} \mathrm{C}\left(+0.2{ }^{\circ} \mathrm{C}\right.$ per cycle $) 90 \mathrm{~s}$, $72{ }^{\circ} \mathrm{C} 40 \mathrm{~s}$ and final elongation at $72{ }^{\circ} \mathrm{C}$ for $30 \mathrm{~min}$; HBD1 singleplex: The initial denaturation was at $95{ }^{\circ} \mathrm{C}$ for $11 \mathrm{~min}$, followed by 35 cycles of $94{ }^{\circ} \mathrm{C} 20 \mathrm{~s}, 55^{\circ} \mathrm{C} 60 \mathrm{~s}, 72{ }^{\circ} \mathrm{C} 45 \mathrm{~s}$ and final elongation at $72{ }^{\circ} \mathrm{C}$ for $30 \mathrm{~min}$.

Post PCR purification was optional, but recommended, to eliminate dye blobs and to concentrate/dilute the samples by variation of the elution volume (e.g. MinElute PCR purification kit, QIAGEN) [26,41].

\subsubsection{Capillary electrophoresis (CE)}

The participating laboratories used standard, multi-color fluorescent genetic analyzers and standard electrophoresis conditions for the detection of the menstrual blood, vaginal secretion and housekeeping gene specific amplicons (Table S2). Any dye set that included FAM and NED, with associated internal lane standard, could be used. Raw data were analyzed with GeneScan ${ }^{\circledR}$ or Genemapper ${ }^{\circledR}$ Software (Life Technologies). For data compilation, the threshold for a positive result was set to 100 RFUs (relative fluorescence units) or 200 RFUs (Genetic Analyzer 3500 series) respectively, for consistency between laboratories and to avoid inclusion of false positive results (due to the presence of dye blobs and baseline noise).

\subsubsection{DNA-amplification and -detection}

If DNA was co-extracted, the laboratories were asked to use a standard STR typing kit, PCR and CE conditions of their choice (Table S2). A peak detection threshold of 50 RFUs was used.

\section{Results}

Laboratories 1-20 participated in exercise 4 and laboratories 1$9,11-24$ participated in exercise 5 . Each laboratory was asked to complete a questionnaire describing the methods used (Table S2). The 24 laboratories used 6 different kits for RNA only or RNA/DNA co-extraction, 6 different reverse transcription kits, 9 different STR typing kits for DNA analysis, 7 different thermocyclers, 4 different genetic analyzers and 3 different polymers (Table S2). Since 3 packages experienced longer shipping times at outside/room temperature, primer mixes may have been impaired. Slightly reduced sensitivities were reported with the vaginal markers ( 8 and 10 days in transit), but no impairment was detected with the menstrual blood multiplexes (20 days in transit). Since no significant adverse effects were observed (slight reduction in sensitivity could be due to other contributing factors as well), results from these laboratories were included in the final analysis.
While unfortunate, the delays have provided some useful information regarding the robustness of the consumables and mRNA.

\subsection{RNA results}

The mRNA profiling results are summarized in Table 2. All 24 laboratories were able to perform the method successfully as demonstrated by detection of the RNA menstrual blood, vaginal secretion and housekeeping gene markers. No results for stains 913 were available for laboratory 7 due to incorrect manipulation of the stains, but results were obtained for all other samples in the exercises.

The 6 menstrual blood and 6 vaginal secretion stains were identified correctly by all laboratories (Table 2). The MMPs, MSX1 and LEFTY2 were detected in most menstrual blood samples (stains 1,3-4,6-8) by more than half of the laboratories, but SFRP4 was only detected in the high input menstrual blood samples 3 and 6. MYOZ1, CYP2B7P1, MUC4, HBD1 and at least one of the lactobacilli markers were reliably detected in the vaginal secretion samples (stains $9-10,12-14,16)$. Stains 8 (1/4 fresh menstrual blood swab) and 16 ( $5 \times 5 \mathrm{~mm}$ from fresh sanitary towel $)$ appeared to be challenging possibly due to donor specific light menstrual blood/vaginal secretion flow.

For stain 6, menstrual blood swabs were collected from the same donor on days $1-4$ of menstruation, for stain 7 from another donor on days 1 and 4 , all stored 5 years at room temperature in the dark. Several laboratories were given part of the same menstrual blood swab for analysis. We then evaluated the variation in marker detection amongst the samples from days 1-4 (Table S3). By day 3 and day 4 of menstruation some of the menstrual blood specific markers (MSX1, LEFTY2, SFRP4) tended to disappear, whereas the metalloproteinase markers (MMP7, MMP10, MMP11) were detected for most of the days of menstruation, with some (possible intra-individual) variation. Variation in gene expression is expected over the reported days of menstruation, especially towards the end of menstruation, as menstrual blood flow can vary significantly [42]. For stain 13, vaginal swabs were collected from the same donor on days $5,7,13$, 20,24 and 28 of the menstrual cycle (stored 5 years at room temperature in the dark). Some laboratories were given a quarter of the same vaginal swab for analysis (in one instance, 3 labs using one of the samples and 4 labs using another). The results were similar for all time points and markers and are therefore collated into one result (Table 2, stain 13). Representative electropherograms of menstrual blood and vaginal secretion stains are shown in Figs. 1 and 2.

In exercise 4, two non-menstrual blood samples (stain 2: blood; stain 5: vaginal secretion) and in exercise 5, two nonvaginal secretion samples (stain 11: urine; stain 15: saliva) were included in order to evaluate the specificity of the included menstrual blood and vaginal secretion markers. MMP7 and MSX1 were detected by more than half of the laboratories in stain $5(1 / 4$ vaginal swab), and MUC4, HBD1, MYOZ1, Ljen and Lgas were detected in stains 11 (1/2 urine swab) and 15 (1/2 buccal swab). Minor occurrences of cross reactivity were observed for the other markers by a small number of laboratories (Table 2). In general, the cross reactive peaks showed reduced signal intensities compared to those of menstrual blood and vaginal secretion samples (Table S4).

For the dilution series, the HKG 3plex markers were detected by most laboratories down to the smallest sample size (1/64 menstrual swab) (Table 3). The MMP markers, whereof MMP10 was the most sensitive, were detected by more than half of the laboratories down to the smallest sample size. MSX1 was detected by more than half of the laboratories in $1 / 8$-sized 
a
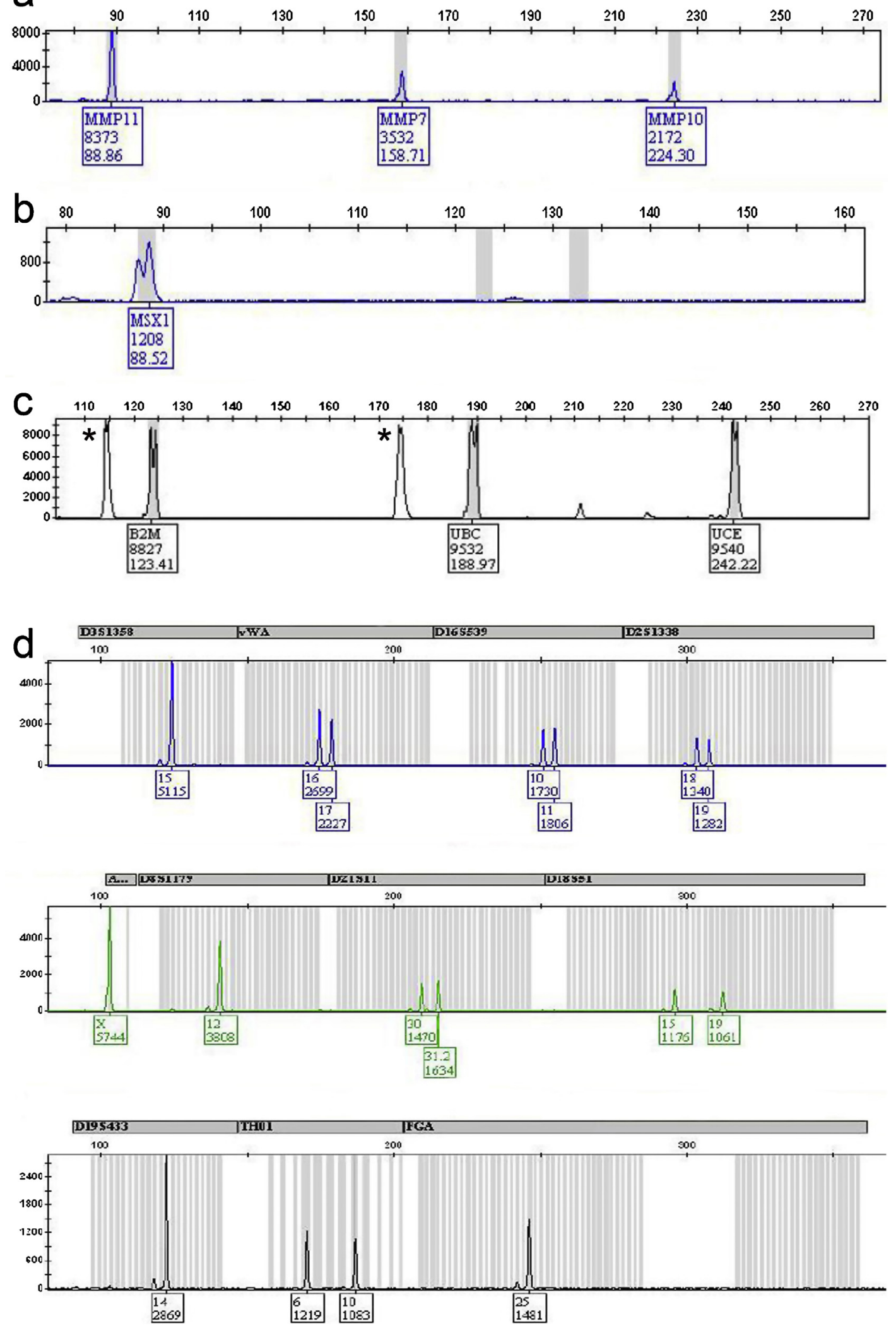

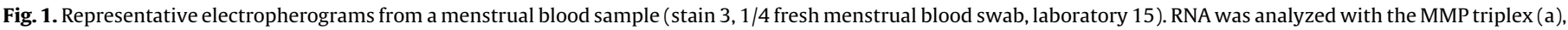
the MB triplex (b) and the HKG triplex (c). DNA was analyzed with the SGMplus kit (d). Overflow peaks are marked with an asterisk (*).

menstrual swabs, but only sporadically in smaller sample sizes. LEFTY2 and SFRP4 were the least sensitive markers and were detected only by a few laboratories (even in high input samples). MYOZ1, CYP2B7P1, MUC4, HBD1, Ljen and Lcris were also detected by most laboratories down to the smallest sample size (1/64 vaginal swab) (Table 3 ). Lgas was only sporadically detected throughout the range of sample sizes tested, which might be due to the limited co-presence of different Lactobacilli 

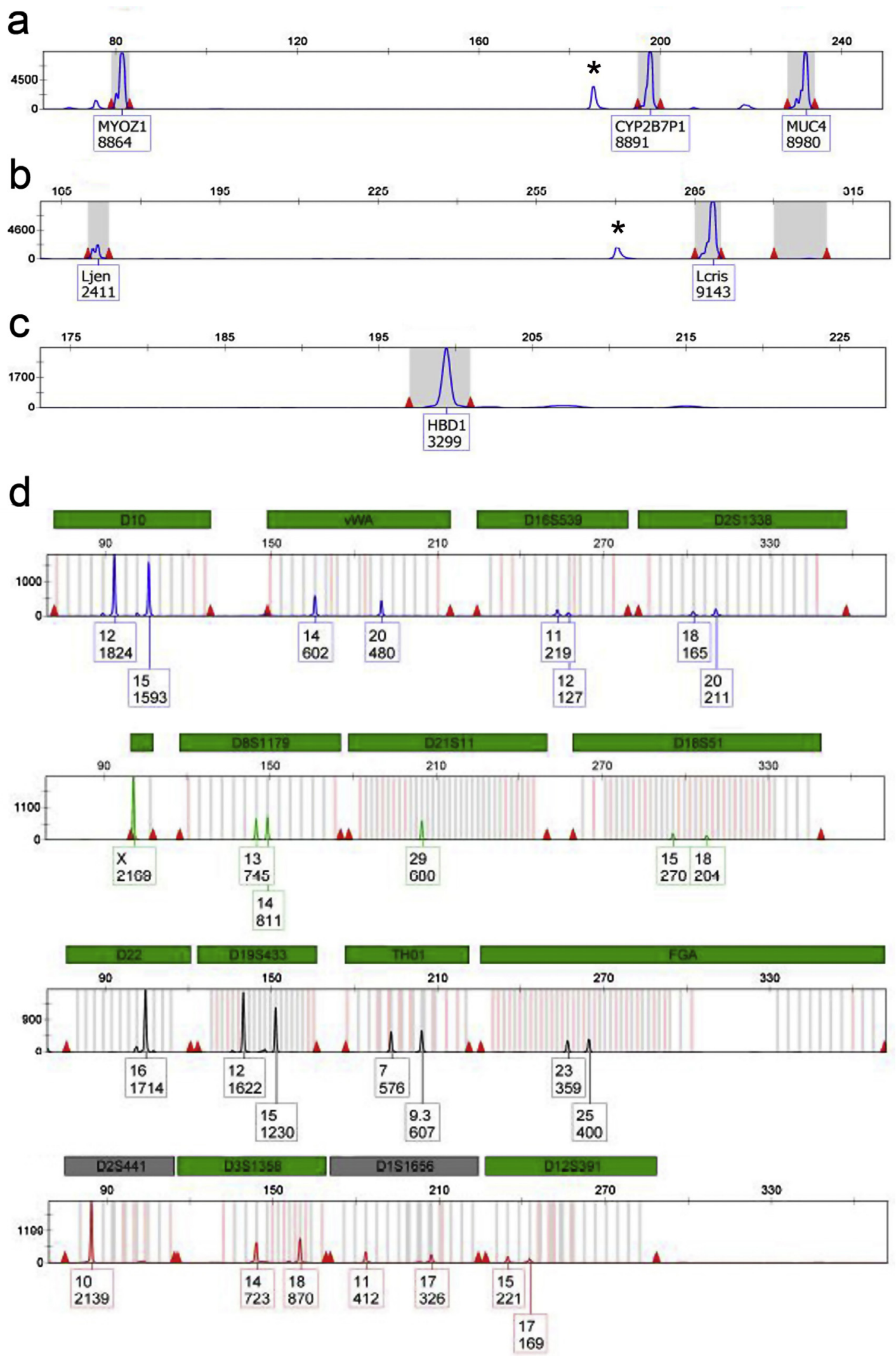

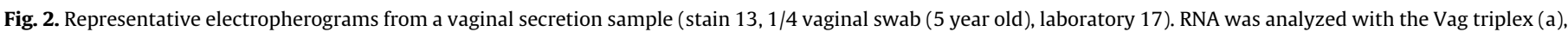
the Lacto triplex (b) and the HBD1 singleplex (c). DNA was analyzed with the NGM kit (d). Overflow peaks are marked with an asterisk (*).

within one individual (see Section 4) rather than the detection sensitivity per se of the marker.

Only sporadic peaks were detected in the RT minus (no reverse transcriptase added) or PCR negative controls (data not shown). In exercise 5 , eight laboratories detected 1,2 or all 3 Lacto markers in RT minus controls. In most, but not all, cases the peaks in the RT minus controls were considerably smaller than the respective peaks in the RT plus samples. Additionally, 
Table 3

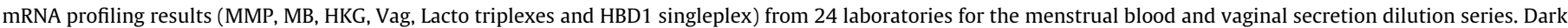

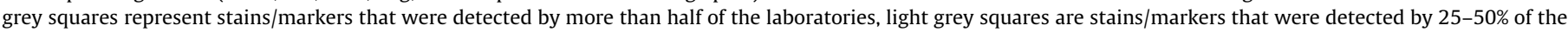
laboratories and white squares represent stains/markers that were detected by $<25 \%$ of the laboratories.

\begin{tabular}{|c|c|c|c|c|c|c|c|c|c|c|}
\hline \multirow[b]{2}{*}{ Sample } & \multicolumn{4}{|l|}{ MMP triplex } & \multicolumn{3}{|c|}{ MB triplex } & \multicolumn{3}{|c|}{ HKG triplex } \\
\hline & MMP11 & MMP7 & & MMP10 & MSX1 & LEFTY2 & SFRP4 & B2M & UBC & UCE \\
\hline $1 / 4$ & $15 / 20$ & $16 / 20$ & & $19 / 20$ & $11 / 20$ & $7 / 20$ & $3 / 20$ & $20 / 20$ & $20 / 20$ & $20 / 20$ \\
\hline $1 / 8$ & $14 / 20$ & $13 / 20$ & & $18 / 20$ & $12 / 20$ & $4 / 20$ & $6 / 20$ & $20 / 20$ & $20 / 20$ & $20 / 20$ \\
\hline $1 / 16$ & $13 / 20$ & $15 / 20$ & & $17 / 20$ & $10 / 20$ & $4 / 20$ & $2 / 20$ & $20 / 20$ & $19 / 20$ & $20 / 20$ \\
\hline $1 / 32$ & $12 / 20$ & $9 / 20$ & & $17 / 20$ & $3 / 20$ & $3 / 20$ & $3 / 20$ & $20 / 20$ & $20 / 20$ & $19 / 20$ \\
\hline \multirow[t]{2}{*}{$1 / 64$} & $7 / 20$ & $9 / 20$ & & $14 / 20$ & $3 / 20$ & $4 / 20$ & $3 / 20$ & $19 / 20$ & $19 / 20$ & $15 / 20$ \\
\hline & \multicolumn{4}{|c|}{ Vag triplex } & & \multicolumn{2}{|c|}{ Lacto triplex } & & & Singleplex \\
\hline Sample & MYOZ1 & & CYP & & MUC4 & Ljen & Lcris & & & HBD1 \\
\hline $1 / 4$ & $23 / 23$ & & $23 / 23$ & & $23 / 23$ & $22 / 23$ & $21 / 23$ & & & $22 / 23$ \\
\hline $1 / 8$ & $22 / 23$ & & $22 / 23$ & & $21 / 23$ & $22 / 23$ & $21 / 23$ & & & $19 / 23$ \\
\hline $1 / 16$ & $21 / 23$ & & $21 / 23$ & & $20 / 23$ & $21 / 23$ & $21 / 23$ & & & $16 / 23$ \\
\hline $1 / 32$ & $19 / 23$ & & $21 / 23$ & & $20 / 23$ & $21 / 23$ & $19 / 23$ & & & $14 / 23$ \\
\hline $1 / 64$ & $15 / 23$ & & $19 / 23$ & & $19 / 23$ & $20 / 23$ & $18 / 23$ & & & $12 / 23$ \\
\hline
\end{tabular}

Ljen was detected in extraction or PCR negative controls by two laboratories.

Only two laboratories in exercise 4 and four laboratories in exercise 5 quantified the RNA: One used the Quant-iT ${ }^{\mathrm{TM}}$ RNA assay kit as well as the Bioanalyzer; one used the Quant-iT ${ }^{\mathrm{TM}}$ RiboGreen ${ }^{\circledR}$ RNA Assay kit and two used a Nanodrop microvolume spectrophotometer (Table S5). Despite the small stain sizes and the different quantification methods, the RNA quantification results correlated quite well, in that the body fluid dilution series showed decreasing RNA amounts and high/low level stains could be differentiated (Table S5). Since only a small number of laboratories performed RNA quantitation, there was insufficient data in order to determine the correlation (if any) between the quantification result and RNA profiling success.

Post-PCR purification resulted in increased peak heights and reduced baseline signal noise but did not allow for detection of additional markers that were not observed prior to post-PCR purification. Eight laboratories in exercise 4 and 7 laboratories in exercise 5 performed post-PCR purification.

\subsubsection{Comparison to other multiplexes}

Two laboratories additionally tested the extracted RNA/cDNA with their own body fluid specific multiplexes, a 19plex from NFI [32] in EDNAP RNA exercise 4 and the CellTyper 11plex from ESR $[23,24]$ in EDNAP RNA exercise 5. The 19plex includes the 2 menstrual secretion markers MMP7 and MMP11 with different primer sets than used in the MMP 3plex. The 19plex and the MMP 3 plex results were difficult to compare, because different cDNA dilutions, PCR cycle numbers and CE injection voltage/time were applied (19plex data not shown). However, the menstrual blood stains and menstrual blood dilution series were identified correctly with both multiplexes. Additionally, the 19plex provided indications for stains 2 and 5 to be blood and vaginal secretion and also identified the body fluid dilution series as blood, saliva and semen. The CellTyper 11plex includes the 2 vaginal markers Lcris and Lgas with different primer sets than used in the Lacto 3 plex. The results of the CellTyper 11plex (data not shown) and Lacto 3plex were in good agreement for stains 9-16 and the vaginal secretion dilution series. Additionally, the CellTyper 11 plex identified stain 15 successfully as saliva.

\subsection{DNA results}

A total of 19 and 22 laboratories (exercise 4 and 5, respectively) performed RNA/DNA co-extraction. No specification for DNA analysis was provided. Various STR typing kits and cycle numbers were utilized by the participating laboratories (Table S2). Full STR profiles were obtained from all stains and the menstrual blood/vaginal secretion dilution series (down to the $1 / 64$ swab) by most laboratories (data not shown). The obtained genotypes were confirmed by comparison with reference profiles. A total of 15 and 19 laboratories (exercise 4 and 5, respectively) quantified the DNA using different quantification systems. Due to the small stain sizes and the different extraction and quantification methods used, the DNA quantification results were difficult to compare. However, the results were in the same order of magnitude for each particular stain (Table S6). Overall, the results demonstrated that DNA of sufficient quantity and quality for STR analysis could be simultaneously extracted with RNA from small amounts of dried stains.

3.2.1. RNA and DNA results of the blood/semen/saliva dilution series

Dilution series of blood (1-0.001 $\mu \mathrm{l})$, semen $(5-0.04 \mu \mathrm{l})$ and saliva (25-0.2 $\mu \mathrm{l}$ ) were tested with the HKG triplex to test these housekeeping genes for their suitability as positive control for the presence of biological material and for successful RNA extraction/ reverse transcription. These body fluid dilution series were prepared in such a way that loss of the housekeeping gene markers by dilution could be observed. Since saliva and semen are known to exhibit reduced housekeeping gene activity, higher input amounts of saliva and semen were used. Most laboratories performed RNA/DNA co-extraction on these samples and could provide RNA and DNA results. Some of these housekeeping genes could be detected down to $0.01 \mu \mathrm{l}$ blood, $0.2 \mu \mathrm{l}$ semen and $1 \mu \mathrm{l}$ saliva (Table S7). Based on these dilution series, B2M and UBC seemed to be more sensitive than UCE for all tested body fluids. STR profiles could be recovered down to about the same amounts, except for semen where partial profiles down to $0.04 \mu$ l were reported (Table S7). On the other hand good RNA results (B2M and UBC) could be obtained from $0.01 \mu$ l blood, whereas poor STR results were obtained from this same amount of blood.

\subsubsection{RNA and DNA results of the optional stain samples}

The laboratories were invited to analyze additional samples including bona fide and mock casework samples, non-menstrual blood, non-vaginal secretion and non-human samples. Forty-nine menstrual blood samples, 28 non-menstrual blood samples (blood, saliva, semen, urine, vaginal secretion, skin) and 5 non-human samples (cat, dog, chimpanzee) were tested by 12 laboratories with the menstrual blood multiplexes. Fifty-five vaginal samples, 12 menstrual blood, 52 non-vaginal samples (blood, saliva, semen, skin, anal) and 2 non-human samples (cat, dog) were tested by 16 
laboratories with the vaginal and housekeeping gene markers. At least one of the specific markers was detectable in almost all menstrual blood and vaginal secretion stains (Tables S7 and S8), including various stain sizes, storage periods and storage conditions. Vaginal markers were also detected in menstrual blood stains as is expected since menstrual blood is a complex mixture of menstrual blood, peripheral blood and vaginal secretions. For the menstrual blood stains, only one sample showed no RNA result at all (body fluid specific markers and housekeeping genes), perhaps due to limited cell amount, but a DNA profile could be generated. For two other menstrual blood stains housekeeping genes were detected, but no body fluid specific marker. This may be attributed to the presence of a limited amount of actual menstrual blood in the sample but sufficient biological material (e.g. vaginal secretion) present to permit detection of the housekeeping genes. Two vaginal secretion stains were negative for vaginal specific markers: One endovaginal swab from a 13 year old girl and another specified as underwear from a man in a rape case. In the latter case the presence of the stain being from this source might be uncertain or not enough female cell material was present.

Sporadic cross reactive peaks (most of them $<1000$ RFUs) were observed with the menstrual blood markers in blood, saliva, semen and more prominently in a skin sample (described as 'human skin wound') and several vaginal swabs (not specified at which day of cycle) (Table S8). The 3 housekeeping genes performed well in all human stains tested, only UCE appeared to perform less well in saliva samples (Table S8). Only sporadic peaks were observed with the vaginal markers in blood and skin, but several cross reactive peaks in saliva and semen were observed (mainly from Ljen) (Table S9). Full autosomal STR profiles were obtained for most samples where an RNA/DNA co-extraction was performed (data not shown).

\section{Discussion}

The purpose of this exercise was to evaluate an RNA/DNA coextraction strategy with challenging menstrual blood and vaginal secretion samples and novel menstrual blood- and vaginal secretion-specific mRNA multiplexes ( 2 menstrual blood triplexes including the markers MMP7, MMP10, MMP11, MSX1, LEFTY2, SFRP4 as well as 2 vaginal secretion triplexes including the markers MYOZ1, CYP2B7P1, MUC4, Ljen, Lcris, Lgas) and a HBD1 singleplex. In addition, a housekeeping gene triplex (B2M, UBC, UCE) was tested to confirm the presence of RNA of sufficient quantity and quality for analysis. Co-extracted DNA was analyzed with various commercial STR typing kits.

All participating laboratories successfully applied the method using their own laboratory equipment and different kits and chemicals for RNA only or RNA/DNA co-extraction, reverse transcription and PCR. The samples to be analyzed in this exercise were challenging because the laboratories did not know the tissue origin and some stains were low template samples. The differing sensitivities between the laboratories can be explained by the different extraction kits and reverse transcription chemistries used. In addition, it is not possible to prepare identical stains for so many laboratories, different swabs and even different parts from the same swab can contain different cell amounts. And some packages experienced longer transit times at outside/room temperature, which could have impaired the primer mixes.

The evaluated menstrual blood markers proved to be specific, apart from single positive reactions with non-menstrual blood stains (mainly vaginal secretion). Towards the end of menstruation, as menstrual blood flow can be significantly lighter, some of the menstrual blood specific markers (MSX1, LEFTY2, SFRP4) tended to disappear, whereas the metalloproteinase markers were detected for most days of menstruation. We could not confirm the reported reduced expression of MMP11 on day 1 [5], which might be due to the time point of sample taking and inter-individual differences. Amongst the menstrual blood markers, the metalloproteinase markers exhibited the highest sensitivity with more than half of the laboratories detecting all three markers with as little as $1 / 16$ of a swab and MMP10 detected by more than half of the laboratories with as little as 1/64 swab. The sensitivity for MSX1, LEFTY2 and SFRP4, was considerably lower than those observed for the metalloproteinase markers. MSX1 was detected by more than half of the laboratories down to $1 / 16$ of a swab, while LEFTY2 and SFRP4 were not detected by more than half of the laboratories for any of the sample sizes.

All of the evaluated vaginal secretion markers were able to detect vaginal secretion. However, MUC4 and HBD1 cross-reacted with other body fluids (mainly saliva) as has been reported previously $[12,21,37,43]$. It was reported that predominance of one Lactobacillus species is common in vaginal microbial populations $[44,45]$. In particular, 4 species of this genus ( $L$. iners, $L$. crispatus, $L$. gasseri, L. jensenii) are mainly represented in women from different regions and ethnic groups with very limited evidence of their copresence in the same host $[44,45]$. The results from this study appear to support that finding in that most vaginal samples exhibited only one of the 2 species Lcris or Lgas. Ljen was detected in the majority of the samples, but also in some negative controls, suggesting the possibility of general Ljen contamination in the environment as a possible reason for these results. A potential drawback of vaginal specific Lactobacillus markers is, that they are also detected on body sites close to (female groin) or in contact with (penis) the vagina, albeit this was tested only in small sample sizes [46]. The sensitivity was good for all evaluated vaginal secretion markers. MUC4, HBD1 and Ljen results should be interpreted carefully because of their cross-reactive potential. After the commencement of this study, a new vaginal marker (Mesothelin, MSLN) was described [47]. However, a large sample to sample variation and some cross reactivity with saliva was evident. This marker should be subjected to a validation exercise similar to the one described here to determine whether it offers superior sensitivity and specificity in comparison to any of the tested markers. In summary, most of the evaluated menstrual blood and vaginal secretion markers proved to be specific and sensitive and therefore suitable for forensic stains, even for aged and low template samples.

Expression analysis of housekeeping genes was evaluated as a positive control for the presence of biological material and a successful extraction and reverse transcription of RNA of sufficient quality and quantity for analysis. The sensitivity of housekeeping gene detection was in the same range as the body-fluid-specific markers $[26,39,40]$ and STR analysis (Table S7), though slightly reduced in saliva and semen compared to the saliva and semen specific markers [40]. Two of the housekeeping genes tested in this study, B2M and UBC, proved to be quite sensitive and were detected in most body fluid stains (Table S8). Moreno et al. tested the expression levels of a selection of housekeeping genes and showed B2M to be expressed most consistent among body fluids [48]. Based on our data, these housekeeping genes do not appear to be particularly good positive controls in the sense that they should reliably show positive results when biological material is present. At least for saliva and semen, they are less sensitive than the body fluid specific genes. Anyhow, they can be useful for the interpretation of results together with RNA and DNA data. If for example, housekeeping gene expression analysis and STR profiling is successful but no body fluid specific genes are detected, the biological source material might be another, not tested body fluid or tissue. If on the other hand STRs can be detected, but no RNA profiling of either housekeeping or body fluid specific genes were obtained, sensitivity might be a problem. There is no consensus yet 
as to whether housekeeping gene detection should be a requirement for RNA based body fluid identification assays. More studies are warranted in this area.

Another issue is the development of suitable interpretation guidelines, such as those suggested by Lindenbergh et al. [32] or Roeder et al. [34]. What criteria should one use when considering the likely presence or absence of a particular fluid, given the absence/presence and/or relative peak heights of specific markers? How many and which markers should at least be present to identify a body fluid? In general, any false positive reduces the reliability of a test, therefore further investigations on specificity would be useful.

RNA and DNA quantification results were reasonably consistent among laboratories in that high/low input samples could be differentiated and the dilution series showed a monotonic gradual decrease in analytical signal. When comparing absolute numbers, the variation was of course quite high and standard deviations were in the same range as the mean values. This can easily be explained by the different extraction and quantification methods used by the laboratories. None of the suggested RNA quantification systems are ideal as they are not human-specific.

Two laboratories additionally used their own multiplexes (a 19plex from NFI and CellTyper 11plex from ESR) to identify the stains and dilution series. The results regarding menstrual blood and vaginal secretion were concordant. No detailed comparisons with multiplexes were performed since that was not the primary object of this study.

The following negative controls were included in RNA analysis: (1) RT minus (no reverse transcriptase added) to identify possible contaminating DNA (frequently a larger size than the expected RNA product) or the presence of pseudogenes (same size as RNA product) and (2) amplification blank. In exercise 4, only sporadic peaks appeared in the RT minus controls and are regarded as outliers. In exercise 5, eight laboratories found 1, 2 or 3 Lacto peaks in RT minus controls. This was most probably due to genomic DNA contamination since 4 of these laboratories did not use the recommended TURBO DNA-free DNase treatment. In addition, 2 laboratories found Ljen peaks in extraction or PCR negative controls, which could be due to crosstalk/carryover [49] or a general Ljen environmental contamination in the laboratory or contamination of the primer mix.

The possibility of co-extracting RNA and DNA from the same stain sample is an important operational consideration since the amount of sample is often limited in forensic casework. From almost all stains, good quality DNA profiles and the positive identification of menstrual blood and vaginal secretion could be achieved, even for aged stains and those exposed to un-controlled humidity.

In summary, the results of this study support an RNA/DNA coextraction strategy allowing for positive identification of the tissue/fluid source of origin by mRNA profiling as well as a simultaneous identification of the body fluid donor by STR profiling. Most of the evaluated menstrual blood and vaginal secretion markers proved to be robust, reproducible and sensitive. Care should be taken with the vaginal markers MUC4, HBD1 and Ljen because of the potential for cross reactivity with other body fluids as well as presence in negative controls in the case of Ljen. Co-extracted DNA from the same stain provided good-quality STR profiles. Together with the precedent RNA exercises [38-40], a set of reliable RNA markers is now available for the identification of the most common forensic body fluids, namely blood, saliva, semen, menstrual blood and vaginal secretion. A subsequent EDNAP mRNA exercise will include an evaluation of mRNA markers for the identification of skin. Another task for future exercises would be the above mentioned development of suitable interpretation guidelines.

\section{Acknowledgements}

Special thanks for support and technical assistance to A.M. Bento (Forensic Genetic and Biology Service, National Institute of Legal Medicine and Forensic Sciences, Coimbra, Portugal), A. Carracedo (Institute of Legal Medicine, University of Santiago de Compostela, Spain), D. Niederwieser (Institute of Legal Medicine, Innsbruck Medical University, Austria), T. Sijen (Netherlands Forensic Institute, The Hague, The Netherlands), J. Stacey (Institute of Environmental Science and Research Ltd., Auckland, New Zealand) and M. Walt (Institute of Legal Medicine, University of Zurich, Switzerland).

\section{Appendix A. Supplementary data}

Supplementary material related to this article can be found, in the online version, at doi:10.1016/j.fsigen.2013.09.009.

\section{References}

[1] K. Virkler, I.K. Lednev, Analysis of body fluids for forensic purposes: from laboratory testing to non-destructive rapid confirmatory identification at a crime scene, Forensic Sci. Int. 188 (2009) 1-17.

[2] T. Akutsu, K. Watanabe, H. Motani, H. Iwase, K. Sakurada, Evaluation of latex agglutination tests for fibrin-fibrinogen degradation products in the forensic identification of menstrual blood, Leg. Med. (Tokyo) 14 (2012) 51-54.

[3] D.J. Baker, E.A. Grimes, A.J. Hopwood, D-dimer assays for the identification of menstrual blood, Forensic Sci. Int. 212 (2011) 210-214.

[4] M. Bauer, A. Kraus, D. Patzelt, Detection of epithelial cells in dried blood stains by reverse transcriptase-polymerase chain reaction, J. Forensic Sci. 44 (1999) 12321236

[5] M. Bauer, D. Patzelt, Evaluation of mRNA markers for the identification of menstrual blood, J. Forensic Sci. 47 (2002) 1278-1282.

[6] M. Bauer, D. Patzelt, A method for simultaneous RNA and DNA isolation from dried blood and semen stains, Forensic Sci. Int. 136 (2003) 76-78.

[7] M. Bauer, D. Patzelt, Protamine mRNA as molecular marker for spermatozoa in semen stains, Int. J. Leg. Med. 117 (2003) 175-179.

[8] M. Bauer, S. Polzin, D. Patzelt, Quantification of RNA degradation by semiquantitative duplex and competitive RT-PCR: a possible indicator of the age of bloodstains? Forensic Sci. Int. 138 (2003) 94-103.

[9] J. Juusola, J. Ballantyne, Messenger RNA profiling: a prototype method to supplant conventional methods for body fluid identification, Forensic Sci. Int. 135 (2003) 85-96.

[10] M. Alvarez, J. Juusola, J. Ballantyne, An mRNA and DNA co-isolation method for forensic casework samples, Anal. Biochem. 335 (2004) 289-298.

[11] J. Juusola, J. Ballantyne, Multiplex mRNA profiling for the identification of body fluids, Forensic Sci. Int. 152 (2005) 1-12.

[12] C. Nussbaumer, E. Gharehbaghi-Schnell, I. Korschineck, Messenger RNA profiling: a novel method for body fluid identification by real-time PCR, Forensic Sci. Int. 157 (2006) 181-186.

[13] J. Ballantyne, Validity of messenger RNA expression analyses of human saliva, Clin. Cancer Res. 13 (2007) 1350, author reply 1351

[14] M. Bauer, RNA in forensic science, Forensic Sci. Int. Genet. 1 (2007) 69-74.

[15] J. Juusola, J. Ballantyne, mRNA profiling for body fluid identification by multiplex quantitative RT-PCR, J. Forensic Sci. 52 (2007) 1252-1262.

[16] M. Bauer, D. Patzelt, Identification of menstrual blood by real time RT-PCR: technical improvements and the practical value of negative test results, Forensic Sci. Int. 174 (2008) 55-59.

[17] M. Setzer, J. Juusola, J. Ballantyne, Recovery and stability of RNA in vaginal swabs and blood, semen, and saliva stains, J. Forensic Sci. 53 (2008) 296-305.

[18] D. Zubakov, E. Hanekamp, M. Kokshoorn, W. van Ijcken, M. Kayser, Stable RNA markers for identification of blood and saliva stains revealed from whole genome expression analysis of time-wise degraded samples, Int. J. Leg. Med. 122 (2008) $135-142$.

[19] C. Haas, B. Klesser, C. Maake, W. Bar, A. Kratzer, mRNA profiling for body fluid identification by reverse transcription endpoint PCR and realtime PCR, Forensic Sci. Int. Genet. 3 (2009) 80-88.

[20] C. Haas, C. Muheim, A. Kratzer, W. Bär, C. Maake, mRNA profiling for the identification of sperm and seminal plasma, Forensic Sci. Int. Genet. Suppl. Series 2 (2009) 534-535.

[21] C. Cossu, U. Germann, A. Kratzer, W. Bär, C. Haas, How specific are the vaginal secretion markers HBD1 and MUC4? Forensic Sci. Int. Genet. Suppl. Series 2 (2009) 536-537.

[22] K. Sakurada, H. Ikegaya, H. Fukushima, T. Akutsu, K. Watanabe, M. Yoshino, Evaluation of mRNA-based approach for identification of saliva and semen, Leg. Med. (Tokyo) 11 (2009) 125-128.

[23] R.I. Fleming, S. Harbison, The use of bacteria for the identification of vaginal secretions, Forensic Sci. Int. Genet. 4 (2010) 311-315. 
[24] R.I. Fleming, S. Harbison, The development of a mRNA multiplex RT-PCR assay for the definitive identification of body fluids, Forensic Sci. Int. Genet. 4 (2010) 244 256.

[25] K. Sakurada, T. Akutsu, H. Fukushima, K. Watanabe, M. Yoshino, Detection of dermcidin for sweat identification by real-time RT-PCR and ELISA, Forensic Sci. Int. 194 (2010) 80-84.

[26] C. Haas, E. Hanson, A. Kratzer, W. Bar, J. Ballantyne, Selection of highly specific and sensitive mRNA biomarkers for the identification of blood, Forensic Sci. Int. Genet. 5 (2011) 449-458.

[27] K. Sakurada, T. Akutsu, K. Watanabe, Y. Fujinami, M. Yoshino, Expression of statherin mRNA and protein in nasal and vaginal secretions, Leg. Med. (Tokyo) 13 (2011) 309-313.

[28] T. Takasaka, K. Sakurada, T. Akutsu, K. Nishigaki, H. Ikegaya, Trials of the detection of semen and vaginal fluid RNA using the genome profiling method, Leg. Med. (Tokyo) 13 (2011) 265-267.

[29] T. Akutsu, H. Motani, K. Watanabe, H. Iwase, K. Sakurada, Detection of bacterial 16S ribosomal RNA genes for forensic identification of vaginal fluid, Leg. Med. (Tokyo) 14 (2012) 160-162.

[30] J.H. An, K.J. Shin, W.I. Yang, H.Y. Lee, Body fluid identification in forensics, BMB Rep. 45 (2012) 545-553.

[31] C. Haas, E. Hanson, J. Ballantyne, Capillary electrophoresis of a multiplex reverse transcription-polymerase chain reaction to target messenger RNA markers for body fluid identification, Methods Mol. Biol. 830 (2012) 169-183.

[32] A. Lindenbergh, M. de Pagter, G. Ramdayal, M. Visser, D. Zubakov, M. Kayser, T. Sijen, A multiplex (m)RNA-profiling system for the forensic identification of body fluids and contact traces, Forensic Sci. Int. Genet. 6 (2012) 565-577.

[33] M.L. Richard, K.A. Harper, R.L. Craig, A.J. Onorato, J.M. Robertson, J. Donfack, Evaluation of mRNA marker specificity for the identification of five human body fluids by capillary electrophoresis, Forensic Sci. Int. Genet. 6 (2012) 452-460.

[34] A.D. Roeder, C. Haas, mRNA profiling using a minimum of five mRNA markers per body fluid and a novel scoring method for body fluid identification, Int. J. Leg. Med. 127 (2012) 707-721.

[35] F. Kohlmeier, P.M. Schneider, Successful mRNA profiling of 23 years old blood stains, Forensic Sci. Int. Genet. 6 (2012) 274-276.

[36] E.K. Hanson, J. Ballantyne, Highly specific mRNA biomarkers for the identification of vaginal secretions in sexual assault investigations, Sci. Justice 53 (2013) 14-22.

[37] J. Jakubowska, A. Maciejewska, R. Pawlowski, K.P. Bielawski, mRNA profiling for vaginal fluid and menstrual blood identification, Forensic Sci. Int. Genet. 7 (2013) $272-278$.

[38] C. Haas, E. Hanson, W. Bar, R. Banemann, A.M. Bento, A. Berti, E. Borges, C. Bouakaze, A. Carracedo, M. Carvalho, A. Choma, M. Dotsch, M. Duriancikova, P. Hoff-Olsen, C. Hohoff, P. Johansen, P.A. Lindenbergh, B. Loddenkotter, B. Ludes, O. Maronas, N. Morling, H. Niederstatter, W. Parson, G. Patel, C. Popielarz, E. Salata,
P.M. Schneider, T. Sijen, B. Sviezena, L. Zatkalikova, J. Ballantyne, mRNA profiling for the identification of blood - results of a collaborative EDNAP exercise, Forensic Sci. Int. Genet. 5 (2011) 21-26.

[39] C. Haas, E. Hanson, M.J. Anjos, W. Bar, R. Banemann, A. Berti, E. Borges, C. Bouakaze, A. Carracedo, M. Carvalho, V. Castella, A. Choma, G. De Cock, M. Dotsch, P. Hoff-Olsen, P. Johansen, F. Kohlmeier, P.A. Lindenbergh, B. Ludes, O. Maronas, D. Moore, M.L. Morerod, N. Morling, H. Niederstatter, F. Noel, W. Parson, G. Patel, C. Popielarz, E. Salata, P.M. Schneider, T. Sijen, B. Sviezena, M. Turanska, L. Zatkalikova, J. Ballantyne, RNA/DNA co-analysis from blood stains - results of a second collaborative EDNAP exercise, Forensic Sci. Int. Genet. 6 (2012) 70-80.

[40] C. Haas, E. Hanson, M.J. Anjos, R. Banemann, A. Berti, E. Borges, A. Carracedo, M. Carvalho, C. Courts, G. De Cock, M. Dotsch, S. Flynn, I. Gomes, C. Hollard, B. Hjort, P. Hoff-Olsen, K. Hribikova, A. Lindenbergh, B. Ludes, O. Maronas, N. McCallum, D. Moore, N. Morling, H. Niederstatter, F. Noel, W. Parson, C. Popielarz, C. Rapone, A.D. Roeder, Y. Ruiz, E. Sauer, P.M. Schneider, T. Sijen, D.S. Court, B. Sviezena, M Turanska, A. Vidaki, L. Zatkalikova, J. Ballantyne, RNA/DNA co-analysis from human saliva and semen stains - results of a third collaborative EDNAP exercise, Forensic Sci. Int. Genet. 7 (2013) 230-239.

[41] P.J. Smith, J. Ballantyne, Simplified low-copy-number DNA analysis by post-PCR purification, J. Forensic Sci. 52 (2007) 820-829.

[42] I.S. Fraser, G. McCarron, R. Markham, T. Resta, Blood and total fluid content of menstrual discharge, Obstetr. Gynecol. 65 (1985) 194-198.

[43] G. Hadzic, A. Lukan, K. Drobnic, Practical value of the marker MUC4 for identification of vaginal secretion in penile swabs, FSI Genet. Suppl. Series 3 (2011) e222-e223.

[44] S. Giampaoli, A. Berti, F. Valeriani, G. Gianfranceschi, A. Piccolella, L. Buggiotti, C. Rapone, A. Valentini, L. Ripani, V. Romano Spica, Molecular identification of vaginal fluid by microbial signature, Forensic Sci. Int. Genet. 6 (2012) 559-564.

[45] J. Ravel, P. Gajer, Z. Abdo, G.M. Schneider, S.S. Koenig, S.L. McCulle, S. Karlebach, R. Gorle, J. Russell, C.O. Tacket, R.M. Brotman, C.C. Davis, K. Ault, L. Peralta, L.]. Forney, Vaginal microbiome of reproductive-age women, Proc. Natl. Acad. Sci. U.S.A. 108 (Suppl 1) (2011) 4680-4687.

[46] C.C.G. Benschop, F.C.A. Quaak, M.E. Boon, T. Sijen, I. Kuiper, Vaginal microbial flora analysis by next generation sequencing and microarrays; can microbes indicate vaginal origin in a forensic context? Int. J. Legal Med. 126 (2012) 303-310.

[47] S.M. Park, S.Y. Park, J.H. Kim, T.W. Kang, J.L. Park, K.M. Woo, J.S. Kim, H.C. Lee, S.Y. Kim, S.H. Lee, Genome-wide mRNA profiling and multiplex quantitative RT-PCR for forensic body fluid identification. Forensic Sci. Int. Genet. 7 (2013) 143-150.

[48] L.I. Moreno, C.M. Tate, E.L. Knott, J.E. McDaniel, S.S. Rogers, B.W. Koons, M.F. Kavlick, R.L. Craig, J.M. Robertson, Determination of an effective housekeeping gene for the quantification of mRNA for forensic applications, J. Forensic Sci. 57 (2012) 1051-1058.

[49] Maximizing the Performance of Capillary Electrophoresis Systems, Applied Biosystems, Forensic News, July (2010). 